\author{
DOROTA MROZEK-BUDZYN ${ }^{1,2}$, RENATA MAJEWSKA ${ }^{1}$, \\ AGNIESZKA KIEŁTYKA ${ }^{1}$, MAŁGORZATA AUGUSTYNIAK ${ }^{1}$
}

\title{
Rubella outbreak in Poland in 2013 - an analysis of surveillance data at the national and province level
}

\begin{abstract}
Introduction. Poland is a member of the WHO European Region where a complete eradication of measles and rubella is planned to be finished by 2015 . Poland accounted for $99 \%$ of all reported rubella cases in $27 \mathrm{EU} / \mathrm{EEA}$ countries in 2013 . It is a good time to evaluate whether the established Polish vaccination strategy was sufficient to reach the goal of rubella elimination in the near future.

Aim. The aim of this study was to analyze the epidemiology of rubella in Poland when the disease outbreak took place in 2013, to determine the reasons of that situation and to find the solution for future rubella elimination strategies.

Material and methods. To analyze the epidemiology of rubella in Poland during the disease outbreak in 2013 the authors used rubella surveillance data collected by the Provincial and National Notifiable Disease Reporting System in 2004-2013. The information at the provincial level derived from one of the 16 provinces (Malopolska). The data on MMR vaccination coverage in 2003-2012 derived from the National Surveillance System. The percentages of rubella cases and vaccine coverage between Poland with Malopolska province were compared.

Results. The outbreak started in late 2012 and continued through 2013, when 38548 rubella cases (incidence rate 100.1/ $100000)$ were notified. Geographically, rubella cases were reported from the entire country, with the highest incidence rate in Malopolska province (254.9/100 000). Only 5 cases from Malopolska and 120 in whole country were laboratory confirmed, the remaining $99.7 \%$ were reported solely on the basis of clinical signs. The vaccination coverage was not sufficient to protect the population against rubella outbreak in Poland, especially among adolescents and young adult males.

Conclusions. The strengthening of routine immunization program and implementation of some additional vaccination campaigns in young adults as well as laboratory confirmation of all suspected cases are the challenges that will have to be met to eliminate rubella in Poland.
\end{abstract}

Keywords: rubella, epidemiological situation, Poland.

DOI: $10.1515 /$ pjph-2015-0026

\section{INTRODUCTION}

Rubella is usually a mild, febrile rash illness in children and adults, however the infection in early pregnancy can result in miscarriage, stillbirth or multiple birth defects, including congenital rubella syndrome (CRS). Congenital malformations have been reported in up to $85 \%$ of infants born to women with confirmed diagnoses of rubella during the first trimester of pregnancy. Available evidence indicates that rubella is a disease that can be eradicated. An intermediate stage to eradicate rubella is its elimination [1]. The earlier suggested feasibility of rubella elimination has been proved in the South and North America where rubella and CRS elimination was announced by Pan American Health Organization in 2010 [2,3].

Poland is a member of the WHO European Region where measles and rubella elimination is planned by 2015 [4]. The disease should be eliminated by using combined measles and rubella vaccines taking form of routine two dose vaccination programs, by achieving and maintaining high coverage and by targeting susceptible population, including women of childbearing age. Rubella vaccine has been available since 1970s and proves highly effective. The one-dose single rubella vaccine (using the vaccine strain Wistar RA 27/3) was introduced in Poland in 1988, targeting only girls aged 12. Earlier, since 1975 all infants had been vaccinated against measles only. The triple vaccine against measles, mumps and rubella (MMR) has been recommended instead of single measles vaccine since the end of 1990s (with extra charge). It was recommended for children at 13-15 month and at 7 year of life in place of mandatory vaccination against measles. However less than $20 \%$ of infants were vaccinated with that strategy in that period of time [5]. The MMR vaccine, using the rubella Wistar RA 27/3 strain, was introduced to childhood mandatory immunization program in 2004 . Initially this immunization program targeted infants at 1314 month of life. One year later, all children aged 12 years and older girls, who had not been vaccinated with singleantigen rubella vaccine before, were additionally vaccinated with MMR. Since 2006 only MMR triple vaccine has been

${ }^{1}$ Department of Epidemiology, Chair of Epidemiology and Preventive Medicine, Jagiellonian University Medical College, Krakow, Poland

${ }^{2}$ The member of Polish National Verification Committee for Measles and Rubella Elimination 
available in Poland and the two-dose MMR (the first dose administered at 13-14 months and the second at the age of 10) vaccine policy was executed as a mandatory vaccination (at no charge). Since 2010 adolescents born between 1997 and 2003, vaccinated with the first dose of MMR at the age of 10 or 12 , were gradually revaccinated with the second dose. According to the current vaccination schedule, all adolescents up to $16^{\text {th }}$ year of life should be vaccinated with two doses of MMR by the end of 2013. The recommended MMR vaccine policy in adulthood was treated as a voluntary option for unvaccinated women of childbearing age [6]. Nowadays, nearly 10 years after MMR vaccine implementation to mandatory immunization program, it is a good time to evaluate whether the established Polish vaccination strategy was sufficient to reach the goal of rubella elimination in the near future.

\section{AIM}

The aim of this study was to analyze the epidemiology of rubella in Poland when the disease outbreak took place in 2013, to determine the reasons of that situation and to find the solution for future rubella elimination strategies.

\section{MATERIAL AND METHODS}

This is a descriptive epidemiological study. The analysis was conducted using rubella surveillance data collected by the Provincial and National Notifiable Disease Reporting System in 2004-2013.

In Poland there are three levels of Surveillance System. Physicians report each rubella case to the local health departments, providing demographic information, International Classification of Diseases (ICD-10) code, case classification and vaccination status. They use the European Union (EU) case definitions for rubella and congenital rubella syndrome (CRS) [7]. Every two weeks, local health departments report the number of cases notified in their area to the provincial health departments that aggregate data, which is then being forwarded to the National Institute of Public Health National Institute of Hygiene. Every month, provincial health departments prepare reports with more detailed data including the number of cases by age group, sex, vaccination status and case classification. Physicians also report to the same Surveillance System annual data on the vaccination coverage among children and adolescents (based on their year of birth) included in their general practice. The information used in our analysis, on both the cases and the vaccination coverage, derived from the national and provincial level (Malopolska province) $[5,8]$.

\section{RESULTS}

When MMR vaccination was introduced to childhood immunization program in 2004, rubella was endemic in Poland, with periodic epidemics occurring approximately every 5 years and seasonal increases in incidence at the end of winter and spring. The vaccination strategy gradually influenced epidemiological situation of rubella - the incidence rate of endemic and epidemic periods was lower compared to pre-vaccination era. This optimistic trend significantly changed in 2013 when the number of cases in Poland sharply increased to 38548 (incidence rate 100.1/100 000). Geographically, rubella cases were reported from the entire country with the highest incidence rate in Malopolska province (254.9/100 000) (Figure 1) and the lowest in Lower Silesian province (18.1/100 000). Two more provinces, Wielkopolska and Lubuskie province, had rubella incidence rates over 200/100 000. Mean incidence rate, calculated from all 16 provinces, equaled 99.9 \pm 71.2 per 100000 . The number of cases began to slowly increase in 2012 , the rise in cases continued by 2013, but at the beginning of 2014 the incidence rate in Poland and Malopolska province was significantly lower compared to the same period of 2013. In endemic years, mostly infants and children were affected by the disease, with similar number of cases in boys and girls. The situation started to change in 2012, when of 743 cases in Malopolska province, males accounted for $88.8 \%$, of which $87.7 \%$ were aged over 15 years (Table 1a). Per 664 reported rubella cases with known vaccination status in 2012, 88.4\% occurred in individuals who had not received rubella vaccine. In 2013 that was $89.4 \%$ (3910 per 4375 cases with known vaccination status). Similar distribution of cases according to age groups was reported on national level in 2012 and 2013 (Table 1b). When rubella incidence rate increased more than 11 times in 2013 compared to the previous year, the outbreak expanded to older age groups, especially males. In Malopolska province in $2013,86.7 \%$ of 8557 cases were persons aged over 15 years, while on national level it was $82.6 \%$. Among rubella cases last year in Malopolska, vaccination history was unknown in $48.5 \%$ of individuals. Regarding the cases with known vaccination status, nearly half of females had been vaccinated (with one or two doses of rubella-containing vaccine) but the majority of males had been unvaccinated. According to available data on national level, the cases had unknown vaccination status less often compared to Malopolska province ( $27.0 \%$ vs. $48.5 \%)$. However, the percentage of unvaccinated cases on national level was similar compared to the studied province ( $83.6 \%$ vs. $89.3 \%$ ). In 2013 , only five cases reported from Malopolska $(0.06 \%)$ were laboratory confirmed, while in the whole country there were 120 such cases $(0.3 \%)$ ) (initially these cases were suspected as measles). The rest of them was clinically diagnosed. Only the measles suspected cases are assigned to be laboratory confirmed. In Poland rubella cases are recognized only on the basis of clinical symptoms. Two CRS cases were reported nationwide in 2013, none of them occurred in Malopolska province.

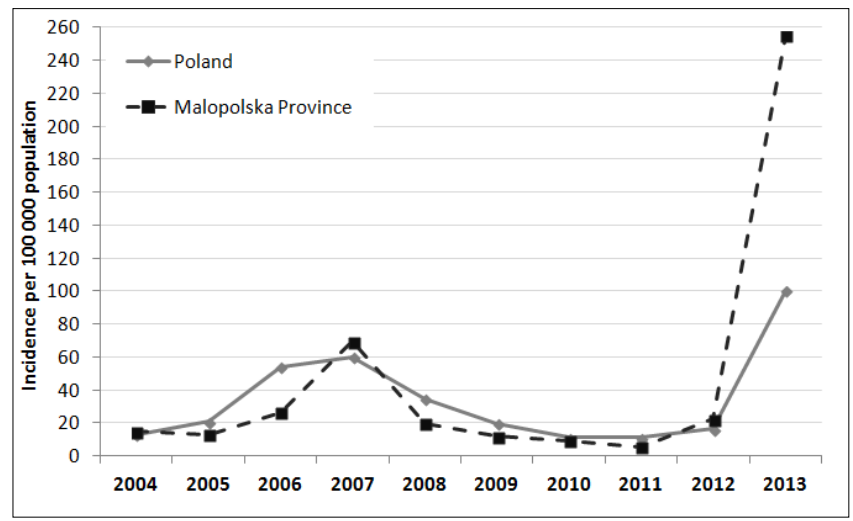

FIGURE 1. Rubella incidence per 100000 population in Poland and Malopolska Province in 2004-2013. 
Rubella population immunity is measured by administrative MMR coverage. After vaccine introduction to mandatory strategy, the MMR coverage in youngest children significantly increased and remained on stable level over the last years (Figure 2). MMR coverage was above $83 \%$ at $2^{\text {nd }}$ year of life, $97 \%$ and $98 \%$ at $3^{\text {rd }}$ and $4^{\text {th }}$ year of life, respectively. The MMR coverage was accounted among the infants who were under control of the surveillance system. About $5 \%$ of children and adolescents were not included in the surveillance system and their vaccination status was unknown. This problem exists within other provinces in Poland on similar level (Figure 3). At the beginning of rubella outbreak at the end of 2012, the MMR coverage in the population included to mandatory vaccination strategy did not significantly differ in Malopolska province compared to average coverage for Poland (Table 2). At the regional level, the second MMR-dose-coverage was lower in ado-lescents aged 14-15 years compared to the national level (71.3\%-72.9\%, and 77.0\%-79.2\%, respectively). The women of childbearing age ( $>15$ years) were mostly vaccinated with one-dose of single rubella vaccine as the girls were aged 12 years. The young males (born before 1997) were not assigned to be vaccinated against rubella.

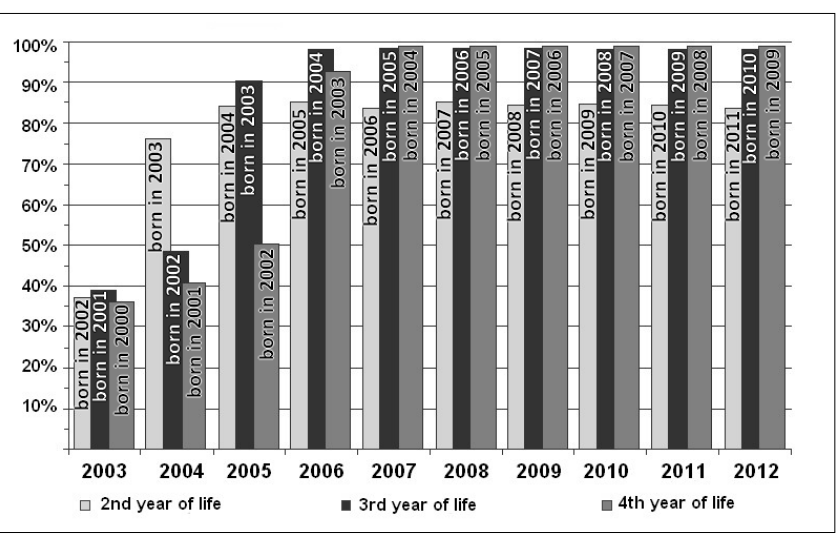

FIGURE 2. The MMR vaccine coverage of Polish infants in 2003-2012 (in relation to children included in vaccination reports).

TABLE 1A. Percentage of rubella cases by age, sex and vaccination status in Malopolska province in 2009-2013.

\begin{tabular}{|c|c|c|c|c|c|c|c|c|c|c|c|}
\hline & & \multicolumn{2}{|c|}{2009} & \multicolumn{2}{|c|}{2010} & \multicolumn{2}{|c|}{2011} & \multicolumn{2}{|c|}{2012} & \multicolumn{2}{|c|}{2013} \\
\hline & & $\mathbf{N}$ & $\%$ & $\mathbf{N}$ & $\%$ & $\mathbf{N}$ & $\%$ & $\mathbf{N}$ & $\%$ & $\mathbf{N}$ & $\%$ \\
\hline total & & 389 & 100 & 307 & 100 & 181 & 100 & 743 & 100 & 8557 & 100 \\
\hline males & & 251 & 64.5 & 159 & 51.8 & 77 & 42.5 & 660 & 88.8 & 7663 & 89.6 \\
\hline females & & 138 & 35.5 & 148 & 48.2 & 104 & 57.5 & 83 & 11.2 & 894 & 10.4 \\
\hline \multicolumn{12}{|c|}{ age groups } \\
\hline \multirow[t]{8}{*}{ males } & 0 & 17 & 6.8 & 10 & 6.3 & 8 & 10.4 & 6 & 0.9 & 44 & 0.6 \\
\hline & $1-4$ & 44 & 17.5 & 55 & 34.6 & 19 & 24.7 & 31 & 4.7 & 169 & 2.2 \\
\hline & $5-9$ & 77 & 30.7 & 62 & 39.0 & 31 & 40.3 & 31 & 4.7 & 273 & 3.6 \\
\hline & $10-14$ & 47 & 18.7 & 27 & 17.0 & 18 & 23.4 & 13 & 2.0 & 225 & 2.9 \\
\hline & $15-19$ & 50 & 19.9 & 2 & 1.3 & 0 & 0.0 & 415 & 62.9 & 4119 & 53.8 \\
\hline & $20-24$ & 10 & 4.0 & 0 & 0.0 & 1 & 1.3 & 115 & 17.4 & 1934 & 25.2 \\
\hline & $25-29$ & 2 & 0.8 & 2 & 1.3 & 0 & 0.0 & 28 & 4.2 & 532 & 6.9 \\
\hline & $\geq 30$ & 4 & 1.6 & 1 & 0.6 & 0 & 0.0 & 21 & 3.2 & 367 & 4.8 \\
\hline \multirow[t]{9}{*}{ females } & 0 & 5 & 3.6 & 11 & 7.4 & 13 & 12.5 & 7 & 8.4 & 33 & 3.7 \\
\hline & $1-4$ & 40 & 29.0 & 47 & 31.8 & 33 & 31.7 & 20 & 24.1 & 137 & 15.3 \\
\hline & $5-9$ & 61 & 44.2 & 64 & 43.2 & 42 & 40.4 & 19 & 22.9 & 185 & 20.7 \\
\hline & $10-14$ & 11 & 8.0 & 11 & 7.4 & 6 & 5.8 & 6 & 7.2 & 76 & 8.5 \\
\hline & $15-19$ & 7 & 5.1 & 4 & 2.7 & 2 & 1.9 & 3 & 3.6 & 91 & 10.2 \\
\hline & $20-24$ & 5 & 3.6 & 2 & 1.4 & 2 & 1.9 & 6 & 7.2 & 50 & 5.6 \\
\hline & $25-29$ & 1 & 0.7 & 4 & 2.7 & 0 & 0.0 & 5 & 6.0 & 49 & 5.5 \\
\hline & $\geq 30$ & 8 & 5.8 & 5 & 3.4 & 6 & 5.8 & 17 & 20.5 & 273 & 30.5 \\
\hline & cination & & & & & & & & & & \\
\hline \multirow[t]{4}{*}{ males } & 1 dose & 61 & 33.2 & 79 & 69.9 & 36 & 65.5 & 41 & 6.8 & 226 & 5.7 \\
\hline & 2 doses & 2 & 1.1 & 10 & 8.8 & 10 & 18.2 & 4 & 0.7 & 42 & 1.1 \\
\hline & not vaccinated & 121 & 65.8 & 24 & 21.2 & 9 & 16.4 & 559 & 92.5 & 3681 & 93.2 \\
\hline & missing data & 67 & & 46 & & 22 & & 56 & & 3714 & \\
\hline \multirow[t]{4}{*}{ females } & 1 dose & 63 & 60.0 & 68 & 74.7 & 41 & 60.3 & 26 & 43.3 & 173 & 40.6 \\
\hline & 2 doses & 0 & - & 1 & 1.1 & 10 & 14.7 & 6 & 10.0 & 24 & 5.6 \\
\hline & not vaccinated & 42 & 40.0 & 22 & 24.2 & 17 & 25.0 & 28 & 46.7 & 229 & 53.0 \\
\hline & missing data & 33 & & 57 & & 36 & & 23 & & 468 & \\
\hline
\end{tabular}




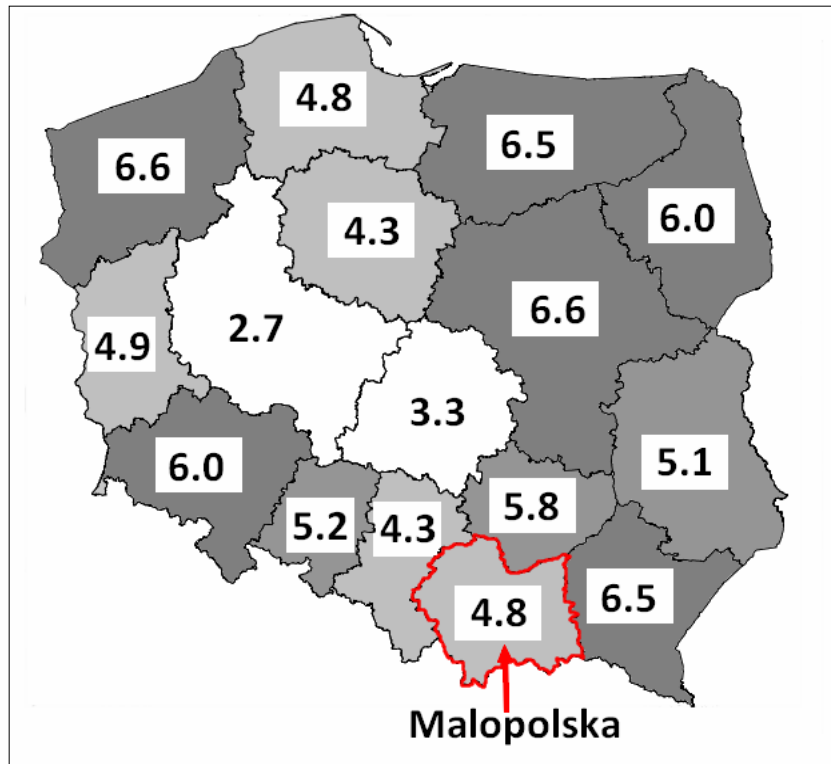

FIGURE 3. Percentage of persons up to 20 years missed in vaccination reports per population, by province in 2012 .

\section{DISCUSSION}

Initially, CRS control activities focused on vaccinating girls and women, what decreased rubella virus transmission but resulted in large proportion of susceptible males. A large population susceptible to rubella infection is at high risk of outbreak and virus transmission to unimmunized pregnant women [9]. This scenario took place in 2013 in Poland. Fortunately, despite 38548 rubella cases reported during last year, only two CRS cases occurred at the same period of time. In last 10 years up to 2013, no CRS or the only one case per year was notified. It is too early to assess the real impact of rubella outbreak on the number of CRS cases because any affected infants would be born 9 months after the 2013 outbreak. Up to the end of October 2014, no CRS case was reported [10].

In 1988, Poland established a goal to prevent CRS, and implemented single rubella vaccine in national immunization program, targeting girls aged 12 years. The MMR vaccine was introduced in 2004 to eliminate measles and rubella, targeting infants aged 12 months and in 2005, children

TABLE 1B. Percentage of rubella cases by age, sex and vaccination status in Poland in 2009-2013.

\begin{tabular}{|c|c|c|c|c|c|c|c|c|c|c|c|}
\hline & & \multicolumn{2}{|c|}{2009} & \multicolumn{2}{|c|}{2010} & \multicolumn{2}{|c|}{2011} & \multicolumn{2}{|c|}{2012} & \multicolumn{2}{|c|}{2013} \\
\hline & & $\mathbf{N}$ & $\%$ & $\mathbf{N}$ & $\%$ & $\mathbf{N}$ & $\%$ & $\mathbf{N}$ & $\%$ & $\mathbf{N}$ & $\%$ \\
\hline total & & 7587 & 100 & 4197 & 100 & 4290 & 100 & 6263 & 100 & 38548 & 100 \\
\hline males & & 4897 & 64.5 & 2417 & 57.6 & 2379 & 55.5 & 4777 & 76.3 & 33796 & 87.7 \\
\hline \multirow[t]{2}{*}{ females } & & 2690 & 35.5 & 1780 & 42.4 & 1911 & 44.5 & 1486 & 23.7 & 4752 & 12.3 \\
\hline & groups & & & & & & & & & & \\
\hline \multirow[t]{8}{*}{ males } & 0 & 195 & 4.0 & 188 & 7.8 & 127 & 5.3 & 154 & 3.2 & 300 & 0.9 \\
\hline & $1-4$ & 725 & 14.8 & 633 & 26.2 & 621 & 26.1 & 498 & 10.4 & 1186 & 3.5 \\
\hline & $5-9$ & 1498 & 30.6 & 814 & 33.7 & 812 & 34.1 & 556 & 11.6 & 1537 & 4.5 \\
\hline & $10-14$ & 1055 & 21.5 & 364 & 15.1 & 287 & 12.1 & 174 & 3.6 & 765 & 2.3 \\
\hline & $15-19$ & 1171 & 23.9 & 325 & 13.4 & 411 & 17.3 & 2617 & 54.8 & 19403 & 57.4 \\
\hline & $20-24$ & 124 & 2.5 & 43 & 1.8 & 63 & 2.6 & 560 & 11.7 & 7206 & 21.3 \\
\hline & $25-29$ & 49 & 1.0 & 20 & 0.8 & 28 & 1.2 & 133 & 2.8 & 1964 & 5.8 \\
\hline & $\geq 30$ & 80 & 1.6 & 30 & 1.2 & 30 & 1.3 & 85 & 1.8 & 1435 & 4.2 \\
\hline \multirow[t]{9}{*}{ females } & 0 & 189 & 7.0 & 155 & 8.7 & 185 & 9.7 & 181 & 12.2 & 279 & 6.0 \\
\hline & $1-4$ & 637 & 23.7 & 517 & 29.0 & 570 & 29.8 & 495 & 33.3 & 971 & 20.9 \\
\hline & $5-9$ & 1284 & 47.7 & 736 & 41.3 & 730 & 38.2 & 443 & 29.8 & 1243 & 26.7 \\
\hline & $10-14$ & 278 & 10.3 & 186 & 10.4 & 230 & 12.0 & 100 & 6.7 & 412 & 8.9 \\
\hline & $15-19$ & 70 & 2.6 & 47 & 2.6 & 55 & 2.9 & 57 & 3.8 & 391 & 8.4 \\
\hline & $20-24$ & 41 & 1.5 & 18 & 1.0 & 24 & 1.3 & 28 & 1.9 & 178 & 3.8 \\
\hline & $25-29$ & 44 & 1.6 & 53 & 3.0 & 31 & 1.6 & 33 & 2.2 & 151 & 3.2 \\
\hline & $\geq 30$ & 147 & 5.5 & 68 & 3.8 & 86 & 4.5 & 149 & 10.0 & 1027 & 22.1 \\
\hline & cination & & & & & & & & & & \\
\hline \multirow[t]{4}{*}{ males } & 1 dose & 1515 & 34.9 & 1183 & 56.9 & 1315 & 62.6 & 884 & 25.9 & 2133 & 8.6 \\
\hline & 2 doses & 60 & 1.4 & 61 & 2.9 & 144 & 6.9 & 64 & 1.9 & 357 & 1.4 \\
\hline & not vaccinated & 2765 & 63.7 & 836 & 40.2 & 643 & 30.6 & 2466 & 72.2 & 22182 & 89.9 \\
\hline & missing data & 557 & & 337 & & 277 & & 1363 & & 9124 & \\
\hline \multirow[t]{4}{*}{ females } & 1 dose & 1312 & 55.7 & 1034 & 68.3 & 1206 & 72.1 & 804 & 67.8 & 1872 & 53.5 \\
\hline & 2 doses & 53 & 2.2 & 42 & 2.8 & 100 & 6.0 & 49 & 4.1 & 246 & 7.0 \\
\hline & not vaccinated & 992 & 42.1 & 437 & 28.9 & 366 & 21.9 & 333 & 28.1 & 1380 & 39.5 \\
\hline & missing data & 333 & & 267 & & 239 & & 300 & & 1254 & \\
\hline
\end{tabular}


aged 10 years also. This vaccination policy was mandatory for all the children included. Furthermore, the MMR was recommended to women before pregnancy who were not vaccinated against rubella or the vaccine was administered to them more than 10 years before pregnancy. According to current immunization program in Poland, children and adolescents up to $17^{\text {th }}$ year of life should be vaccinated with 2-dose MMR vaccine [6]. The routine vaccinations have not been supplemented by any additional campaigns [4]. This vaccination strategy led us to the huge outbreak, when nearly $99 \%$ of rubella cases in Europe were reported from Poland [11]. It was the year when, according to Measles and Rubella Elimination Plan for WHO European Region, we should have been close to elimination of both of these diseases [1].

The MMR vaccination policy established in Poland is an evidence of a failed strategy. It should serve as an example for other countries which are planning their vaccination policies to eliminate rubella. A large proportion of susceptible persons should not be left over because, sooner or later, the outbreak will occur among this population. Such types of outbreaks like in Poland took place also in the other countries and emphasize that vaccination policy should ensure high levels of immunity to all cohorts born since the introduction of rubella vaccine $[12,13]$. Vaccination policy should be conducted either through the routine vaccinations or mass

TABLE 2. The MMR vaccine coverage by year of birth (1997-2011) at the end of 2012.

\begin{tabular}{|c|c|c|c|c|c|c|}
\hline \multirow[b]{2}{*}{$\begin{array}{l}\text { persons } \\
\text { born in }\end{array}$} & \multicolumn{2}{|c|}{ unvaccinated } & \multicolumn{2}{|c|}{ 1-dose MMR } & \multicolumn{2}{|c|}{ 2-dose MMR } \\
\hline & $\begin{array}{l}\vec{Z} \\
\text { ज्ञ̈ } \\
\stackrel{0}{0}\end{array}$ & $\begin{array}{l}\frac{\pi}{\frac{\pi}{0}} \\
\frac{0}{0} \\
\frac{0}{0} \\
\frac{\pi}{2}\end{array}$ & 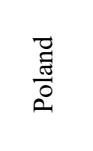 & 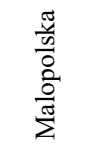 & $\begin{array}{l}\overrightarrow{\vec{E}} \\
\text { 馬 } \\
\text { م }\end{array}$ & $\begin{array}{l}\frac{\pi}{4} \\
\frac{\pi}{0} \\
\frac{0}{0} \\
\frac{0}{\pi}\end{array}$ \\
\hline 2011 & $16.4 \%$ & $16.6 \%$ & $83.6 \%$ & $83.4 \%$ & NA & NA \\
\hline 2010 & $2.1 \%$ & $2.7 \%$ & $97.9 \%$ & $97.3 \%$ & NA & NA \\
\hline 2009 & $1.1 \%$ & $1.5 \%$ & $98.9 \%$ & $98.5 \%$ & NA & NA \\
\hline 2008 & $0.7 \%$ & $0.9 \%$ & $99.3 \%$ & $99.1 \%$ & NA & NA \\
\hline 2007 & $0.5 \%$ & $0.6 \%$ & $99.5 \%$ & $99.4 \%$ & NA & NA \\
\hline 2006 & $0.4 \%$ & $0.5 \%$ & $99.6 \%$ & $99.5 \%$ & NA & NA \\
\hline 2005 & $0.3 \%$ & $0.4 \%$ & $99.7 \%$ & $99.6 \%$ & NA & NA \\
\hline 2004 & $0.2 \%$ & $0.3 \%$ & $99.8 \%$ & $99.7 \%$ & NA & NA \\
\hline 2003 & $0.5 \%$ & $0.3 \%$ & $22.9 \%$ & $15.9 \%$ & $76.6 \%$ & $83.8 \%$ \\
\hline 2002 & $1.1 \%$ & $1.2 \%$ & $28.1 \%$ & $24.5 \%$ & $70.8 \%$ & $74.4 \%$ \\
\hline 2001 & $0.8 \%$ & $1.0 \%$ & $32.1 \%$ & $30.2 \%$ & $67.1 \%$ & $68.7 \%$ \\
\hline 2000 & $0.6 \%$ & $0.7 \%$ & $31.0 \%$ & $30.8 \%$ & $68.4 \%$ & $68.5 \%$ \\
\hline 1999 & $0.5 \%$ & $0.6 \%$ & $20.0 \%$ & $19.6 \%$ & $79.6 \%$ & $79.8 \%$ \\
\hline 1998 & $0.7 \%$ & $0.7 \%$ & $20.1 \%$ & $26.3 \%$ & $79.2 \%$ & $72.9 \%$ \\
\hline 1997 & $0.6 \%$ & $0.8 \%$ & $22.4 \%$ & $28.0 \%$ & $77.0 \%$ & $71.3 \%$ \\
\hline $1996^{1}$ & $34.7 \%$ & $32.9 \%$ & $36.5 \%$ & $41.1 \%$ & $28.7 \%$ & $25.9 \%$ \\
\hline $1995^{2}$ & $43.4 \%$ & $38.2 \%$ & $34.9 \%$ & $40.9 \%$ & $21.7 \%$ & $20.9 \%$ \\
\hline $1994^{3}$ & $49.0 \%$ & $47.4 \%$ & $33.6 \%$ & $40.9 \%$ & $17.4 \%$ & $11.7 \%$ \\
\hline $1993^{4}$ & $81.2 \%$ & $84.0 \%$ & $13.5 \%$ & $12.8 \%$ & $5.3 \%$ & $3.2 \%$ \\
\hline $1992^{5}$ & $98.0 \%$ & $97.3 \%$ & $0.5 \%$ & $1.6 \%$ & $1.6 \%$ & $1.1 \%$ \\
\hline
\end{tabular}

$\mathrm{NA}$ - not applicable because $2^{\text {nd }}$ vaccine dose is administrated at the age of 10 ; ${ }^{1}$ at the end of 2009; ${ }^{2}$ at the end of $2008 ;{ }^{3}$ at the end of 2007; ${ }^{4}$ at the end of 2006; sat the end of 2003; campaigns. Young males in Poland have not been timely identified as a potential gap in the population immunity. The ongoing outbreak has not significantly changed the vaccination policy in Poland. The only change from this year (2014) were MMR recommendations for young adult males unvaccinated with MMR according to mandatory schedule or if the time since first vaccine dose was longer than 10 years. Earlier the same recommendation referred to young females only. These voluntary option recommendations for males are not sufficiently strong to bring significant results. Furthermore, the rubella outbreak revealed that too low MMR coverage in youngest children did not protect this cohort against the rubella virus infection. Among rubella cases in children up to $10^{\text {th }}$ year of life there were many unvaccinated cases and cases with unknown vaccination status. It serves as an evidence of a gap in vaccination surveillance system in such important cohort like the youngest children. About $5 \%$ of the population up to 20 years of age was not under vaccination coverage surveillance. This makes a very important gap in immunization not only for rubella elimination strategy, but even more for measles. In recent years 30-60 measles cases were reported per year in Poland. The number of cases increased up to 88 in 2013 . Only $55 \%$ of measles cases were confirmed by laboratory tests. About $15 \%$ of suspected measles cases were confirmed as rubella cases [4]. On the other hand, it is more likely that many measles cases with atypical course of disease were reported as rubella cases, which was diagnosed on the basis of clinical symptoms only. Having very low incidence rate of measles in the last decade, the majority of physicians have difficulties in diagnosing measles clinically, especially because of the fact, that the cases can currently present mild or atypical symptoms and are shifted to the older age groups. At this stage of rubella epidemiological situation in Poland, physicians should not have problems to diagnose rubella clinically. The lack of laboratory confirmation of rubella cases is not so important for sensitivity of surveillance, on the stage when there is so high incidence of this disease compared to measles in recent years. However, the lack of laboratory confirmation of rubella can negatively influence measles control. Owing to relatively huge rubella outbreak, we have uncertain epidemiological situation with respect to measles which should be close to the target of elimination. The Polish experience is an evidence supporting the implementation of elimination strategies with respect to measles and rubella concurrently $[14,15]$.

The rubella outbreak in Poland has proved that our population has not been protected against rubella. According to the WHO strategy for measles and rubella elimination coverage, $\geq 95 \%$ of the general population with first and second doses of measles and rubella-containing vaccines at the national and subnational administrative levels should be achieved [16]. We have to pay special attention to increase the firstdose MMR coverage among the infants by 24 months of age provided through the routine program. We have been achieving the required vaccination coverage among infants by 36 month of age, with nearly one year of delay compared to the requirements. Furthermore, MMR coverage was counted for infants whose medical records were under surveillance system. It is necessary to include under surveillance about $5 \%$ of children and adolescents who pertain to the gaps 
with unknown vaccination status. The ongoing outbreak has been giving the unprotected cohorts an opportunity to develop natural immunity against rubella but with the risk of disease complications and CRS cases occurrence. Eventually, the rubella outbreak has increased the immunity of many individuals, but the proportion of the population which remained susceptible is not known. Regardless rubella infection history, the unvaccinated young population should be included to the additional vaccination campaigns. However, achieving high MMR coverage in infants will be the most difficult because of decreasing public acceptance of vaccination in Poland. The anti-vaccine organizations that portray themselves as official resources for credible data on vaccines, continue to provide flawed or biased information about MMR and its association with autism or other developmental delays $[17,18]$. This problem, especially related to low acceptance of MMR, has been observed in many countries for recent years [19]. The MMR mandatory strategy has not improved vaccination coverage to the adequate level ( $>=95 \%$ ). Despite the rubella herd immunity threshold required lower rubella vaccine coverage in population $(80 \%)$ [20] compared to measles threshold (95\%) [16], the higher coverage is necessary to achieve both diseases elimination using the triple vaccine. According to Polish law, there are financial penalties for parents who avoid vaccinating their children without adequate contraindications. However, this penalty system does not work efficiently enough. Without better acceptance of MMR vaccination, Poland will not be able to meet the goal of measles and rubella elimination $[21,22]$. Additional studies are necessary to identify the other reasons why, in the routine program, not all of the eligible children are being vaccinated in a timely manner.

Immunization coverage should be monitored both on the national and regional level, since the local authorities are more at a chance of identifying any potential gaps in population immunity. There is an important question, why rubella incidence rate in Malopolska province was 2.5-fold higher in 2013, compared to average incidence in Poland. It seems not to be connected neither with demographic nor social factors. The five provinces with highest rubella incidence rates (>100/100 000) are not more densely populated or economically worse from the others. It could be attributed to differing MMR immunization coverage standards in Polish provinces. On the other hand, the rubella surveillance sensitivity in Malopolska province may be higher compared to the other provinces. One rule usually exists: the greater disease severity, the better surveillance sensitivity. Rubella is rather treated not as a severe disease with self-limiting course that can be one of the reasons of low surveillance sensitivity in some areas [19]. The closer to the state of rubella elimination, the higher a sensitivity of cases surveillance will be required, but at the current stage the most important is the strengthening of MMR vaccination strategy in Poland.

\section{CONCLUSION}

All things considered, inspite of the substantial progress that has been made toward a complete rubella elimination between 2004 and 2012, a resurgence of the disease happened in 2013. The large outbreak occurred mostly among adolescents and adult males. The strengthening of routine immunization program and implementation of some additional vaccination campaigns in young adults as well as laboratory confirmation of all suspected cases are the challenges that will have to be met in order to eliminate rubella in Poland.

\section{REFERENCES}

1. World Health Organization. Eliminating measles and rubella. Framework for the verification process in the WHO European Region. World Health Organization Regional Office for Europe, Copenhagen, Denmark; 2012. [http://www.euro.who.int/_data/assets/pdf_file/0005/156776/e96153Eng-final-version.pdf]

2. Pan American Health Organization. Plan of Action of the documentation and verification of measles, rubella, and congenital rubella syndrome elimination in the region of the Americas. Washington DC: Pan American Health Organization; 2011.

3. Castillo-Solórzano C, Marsigli C, Bravo-Alcántara P, et al. Elimination of rubella and congenital rubella syndrome in the Americas. J Infect Dis. 2011;204:S571-S578.

4. Pasławska A, Mrozek-Budzyn D. Is measles elimination possible in WHO European Region up to 2015? Przegl Epidemiol. 2013;67:451-4.

5. National Institute of Public Health - National Institute of Hygiene. Vaccinations in Poland in 2012. [http://www.pzh.gov.pl/oldpage/ epimeld/2012/Sz_2012.pdf]

6. Mrozek-Budzyn D. The evolution of Polish Immunization Schedule during the last 10 years. Przegl Epidemiol. 2012;66:107-12.

7. European Commission. Commission decision of 19 March 2002 laying down case definitions for reporting communicable diseases to the Community network under Decision No 2119/98/EC of the European Parliament and of the Council. Official Journal of the European Union. Luxembourg: Publications Office of the European Union. Communities. 3.4.2002:L 86/44. [http://eur-lex.europa.eu/ LexUriServ/LexUriServ.do ?uri=OJ:L:2002:086:0044:0062:EN:PDF]

8. National Institute of Public Health - National Institute of Hygiene. Infectious diseases and poisoning in Poland 2004-2013.[http://www. pzh.gov.pl/]

9. World Health Organization. Rubella vaccines: WHO position paper. WHO Weekly epidemiological report. 2011;86:301-16. [http://www. who.int/wer/2011/wer8629.pdf 7]

10. National Institute of Public Health - National Institute of Hygiene. Zachorowania na wybrane choroby zakaźne w Polsce od 1 stycznia do 15 sierpnia 2014 r. oraz w porównywalnym okresie 2013 r. Zakład Epidemiologii NIZP-PZH. [http://www.pzh.gov.pl/oldpage/epimeld/2014/ INF_14_08A.pdf]

11. European Center for Disease Control. Surveillance report. Measles and rubella monitoring. Stockholm: ECDC; 2014.

12. Janta D, Stanescu A, Lupulescu E, et al. Ongoing rubella outbreak among adolescents in Salaj, Romania, September 2011-January 2012. Euro Surveill. 2012;17(7):1-4

13. Centers for Disease Control. Nationwide rubella epidemic - Japan, 2013. MMWR. 2013;62:457-62.

14. Hopkins DR. Disease eradication. N Engl J Med. 2013;368:54-63.

15. World Health Organization. Global measles and rubella strategic plan: 2012-2020. Switzerland: World Health Organization; 2012. [http:// www.measlesrubellainitiative.org/wp-content/uploads/2013/06/Measles-Rubella-Strategic-Plan.pdf].

16. World Health Organization. Eliminating measles and rubella. Framework for the verification process in the WHO European Region. Geneva: World Health Organization 2012. [http://www.euro.who.int/_data/assets/pdf_file/0005/156776/e96153-Eng-final-version.pdf].

17. Casiday R. Uncertainty, decision-making and trust: lessons from the MMR controversy. Community Pract. 2006;79:354-7. 
18. Brown KF, Kroll JS, Hudson MJ, et al. Factors underlying parental decisions about combination childhood vaccinations including MMR: a systematic review. Vaccine. 2010;28:4235-48.

19. Usonis V, Anca I, André F, et al. Rubella revisited: where are we on the road to disease elimination in Central Europe? Vaccine. 2011;29:9141-7.

20. Edmunds WJ, van de Heijden OG, Eerola M, Gay NJ. Modelling rubella in Eur Epidemiol Infect. 2000;125:617-34.

21. Vandermeulen C, Roelants M, Theeten H, et al. Vaccination coverage and sociodemographic determinants of measles-mumps-rubella vaccination in three different age groups. Eur J Pediatr. 2008;167:1161-8.

22. McGreevy D. Risks and benefits of the single versus the triple MMR vaccine: how can health professionals reassure parents? J R Soc Promot Health. 2005;125:84-6.

\section{Corresponding author} Dorota Mrozek-Budzyn

Department of Epidemiology,

Chair of Epidemiology and Preventive Medicine, Jagiellonian University Medical College

7A Kopernik Str., 31-034 Krakow

E-mail: dorotamrozek@tlen.pl 